\title{
THE “OTHER” IMAGE: A TIME-PLACE RIFT IN THE LEBANESE IDENTITY
}

\author{
Noel Nasr* and Dina Nashar Baroud \\ Notre Dame University-Louaize Lebanon, Lebanon
}

\begin{abstract}
In May 2018, the British photographer Chris Coekin and the Lebanese photographer Noel Nasr published a collaborative body of work entitled "The Distance is Always Other." Inspired by an archive produced in 1973 by an elderly couple of American tourists known as Bob and Ann, the archive is a curious mix of vernacular images documenting the Lebanese landscape. The images were produced with a basic stereoscopic camera where two photographs were produced simultaneously through two separate lenses, resulting in two images depicting the same viewpoint. Coekin and Nasr retraced the footsteps of the tourists, applying the idea of two separate images. They each used identical vintage fixed-lens film cameras but with Coekin operating as the left lens while Nasr was the right. Their two final images were overlaid together to form one single image. The visually appealing aesthetic represents the artists' ambitious but flawed attempt to faithfully record the same image, raising questions about the representational limitations of the photograph, whilst engaging the viewer in a unique and intriguing story. In a critical reading of this work, this paper argues that the images produced were conceptualized around the notion of "other": the other individual, the other time and the other place. It furthermore proposes that this otherness bears a strong resemblence to the Lebanese (cultural) identity crisis and complexity. Moreover, the paper argues that the "The Distance is Always Other" signifies a contextual drift; a drift in space and time, hence a quasi-gaze which consolidates the quasi-identity of the Lebanese.
\end{abstract}

Keywords: vernacular photography, Lebanon, other, identity rift

\section{Introduction}

As national and international human crises accelerate, history, memory and even fiction about these become more complex. Wars, violence, migration and alienation have reached an unprecedented rate, pattern and level of complications. Consequently, art, which is in so many ways a reflection of human history, attempts to seek new forms of expression and to imagine and communicate the troubled or traumatic spirit of such acceleration and changing life patterns. History, narration and inspiration have then to be else-wise. But else-wise why and how?

In its strive to maintain its role in recording history, photography for instance, has to pause for a while to reconstitute its recording technique, philosophy and presentation. In this respect, the history of photography (Nickel, 2001) and its significance in being an active part of history-making, including the recording of place, time and events and even its "[contribution in] moulding a new historical sense and new awareness (Minghelli, 2016)," have changed. Photography may need to come to terms with the fact that history might not be solely depicted by places, times, events or even people. In this sense, images about history have to be perceived through a different lens, alternative shooting techniques and distinct space-time preferentiality and imagery.

Moreover, when faced with wars, instability and national complexities, this reconstitution of the role of photography and history is subjected to further re-setting, where photographers have to deal not only with new technical and philosophical scenarios but also with the notion of loss due to war and conflicts: an else-wise loss. With such probability, photography is not only a technical exploration of temporal inconsistencies or creatively displayed images, but also an entity that tries to give a "visual voice", depth and meaning and become one with the lost lives, places, dignity or any other form of loss.

Corresponding Authors’ Email: * nnasr@ndu.edu.lb 
This paper draws on this argument and begins by revisiting the work of English photographer Chris Coekin and Lebanese photographer Noel Nasr, who published a collaborative body of work entitled "The Distance is Always Other", which retraces photographs taken on the eve of the Lebanese civil war. By restaging these photos, "The Distance is Always Other" attempts to portray the Lebanese identity crisis as well as the reconstitution of history through an else-wise geography and temporality. The aim of the work is to highlight some practices which attempt to formulate history, memory and fiction about a nation in crisis, through photographs that question space and identity. By reviewing the work of Coekin and Nasr, the techniques they used, the images they produced and the layout of their oeuvre's exhibition, this paper argues that this troubled and complex era - human crises, re-questioning ontologies - is a time where history leaps and scales are lost (Virilio, 2000), origins are lost (Derrida, 1976), space is no longer defined in its 3D dimensionality (Deleuze and Gauttari, 1987) and individuals are de-voided from their history. Photography therefore takes on the role of recording the loss of time, space and individuals (the subject and the object). In such a discourse, history becomes a documentation of the loss and its materiality (space-time, object-subject). The photographs of Coekin and Nasr demonstrate this through a technique that disperses history as well as identity.

This paper will begin by briefing the Lebanese crisis before exploring the work of Coekin and Nasr and proposing a reading of the techniques they have used. The discussion will then veer to a critical and theoretical review of the photos, with an emphasis on spatial and geographical rifting and temporal slipping, but also on the loss or absence communicated through these image, which symbolizes in many ways the rift that tears through the midst of Lebanese cultural identity.

\section{The Lebanese Identity Crisis and the “Other” Exhibition}

Since Lebanon's independence in the mid 1940s, the Lebanese have been on an unending journey to try and define their identity. The diversity of religions and sects in the country have been the main cause of a barely disguised conflict amongst the country's inhabitants, openly manifested in un-agreed political affiliations to international and regional countries, unstable economical situations/conditions and distinct (sometimes radical) cultural/religious identities and images. Samir Khalef explains this rift further by stating how "the internal disparities are generally a byproduct of deep cultural cleavages inherent in sharp communal, confessional, and other primordial and segmented loyalties (Khalaf, 2002).”

The sharp divisions across the Lebanese landscape have led to constant instability in the country and to a civil war which started in 1975 and lasted for over 15 years. The war was described in many instances as sectarian, with violent clashes all over the country between the nation's two main religions: Christians and Muslims, resulting in the killing and injuring of hundreds of thousands of people. The whole situation was only made worse by the fact each of these religions is divided into different sects, each affiliated to a different country and political power, and more often than not in disagreement with one another's views and policies.

Despite the end of the civil war, Lebanon is still struggling with defining its identity and the country is still reeling from both age-old and modern political and cultural conflicts and complexities.

In such situations of civil war, unrest and conflict, the role of humanities, art and design alike is to attempt to either record history as it appears to be, or to criticize and critically evaluate and analyze its complexity. One such attempt was precisely the intention behind "The Distance is Always Other", which hints, as will be discussed later in this article, at the paradoxical cultural conflicts and differences amongst the Lebanese and their being and feeling as Other, yet within the proximity and short distances of their very own native land. 


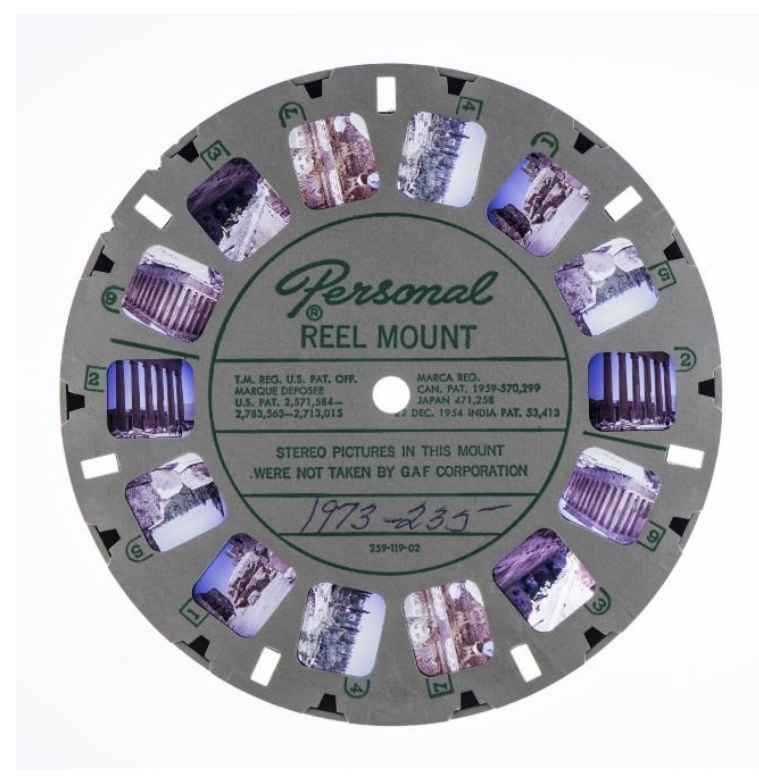

Figure 1: A reel from the archive of Bob and Ann

Published and exhibited in May 2018, the emphasis of "The Distance is Always Other" is the appropriation and investigation of a photographic archive Coekin and Nasr acquired from eBay. The archive was produced in 1973 by an elderly American couple known only as Bob and Ann, who would appear to have travelled to Lebanon as tourists, taking the opportunity to visit various locations. The archive is a curious mix of vernacular images documenting the Lebanese landscape, including its urban, domestic and exotic side (Figure 1). The images offer an insight into a country which was on the very verge of civil war. The archive is unique in that the images were produced with a basic stereoscopic camera. Two photographs were produced simultaneously from two separate lenses resulting in two images depicting the same viewpoint.

Coekin and Nasr retraced the footsteps of the tourists, revisiting the same locations they had photographed fortyfive years ago. Effectively taking on the role of geographical investigators, they painstakingly pieced together the original journey and route. Clearly, over the years, many of the locations had changed dramatically, but many were still recognizable. Coekin and Nasr's contemporary images attempt to appropriate the same visual perspective as the tourists, capturing the equivalent mundane street views, portraits and ancient temples.

Inspired by the tourists' twin-lens camera, the photographers utilized the idea of two separate images faithfully recording the same location as a conceptual strategy. They each used identical vintage fixed lens film cameras with basic technical specifications similar to that of Bob and Ann's camera. In effect, Coekin became the left lens and Nasr the right. Independently of each other and using an original photograph as a reference point, they both attempted to produce the same image with the same viewpoint as the tourists had. As with the original film, Coekin and Nasr's final images were overlaid together to form one final image. The results, born out of an objective task, offer altering viewpoints and an out of synch view. The visually appealing aesthetic represents the artists' ambitious, but flawed attempt to faithfully record the same image, raising questions about the representational limitations of the photograph, whilst engaging the viewer in a unique and intriguing story.

The technical details of the production started with Chris purchasing the archive online and both he and Noel buying an Agfa Isola 1955 vintage camera each. This choice was made for three reasons that meant the experience of the artists was very similar to that of the tourists. Firstly, the $6 \times 6 \mathrm{~cm}$ square format of the film was very close to the size of the stereoscopic images. 


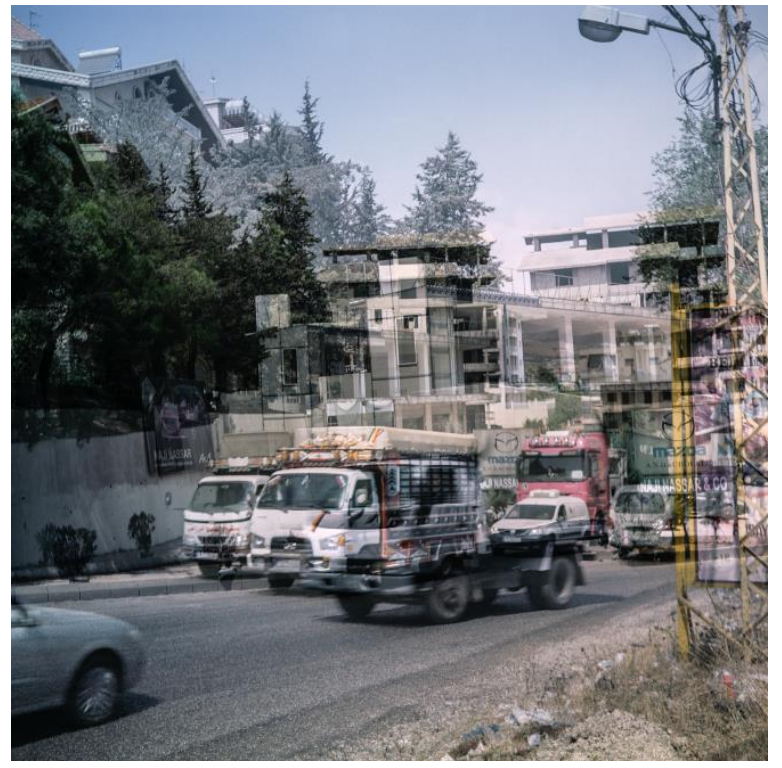

Figure 2: The experimental process produced a two-dimensional photograph that evokes the simulacrum of three-dimensional space felt when looking through the view-master

Secondly, the limited technical options that the camera allowed: manual focus exclusively and only two aperture options and two shutter speeds, made the vernacular photographic experience very alike the American tourists' in 1973. Third and finally was the approximately $50 \mathrm{~mm}$ focal length of the camera's lens (also known as the average focal length) which was the same used by Bob and Ann.

Before retracing the tourists' journey, Noel and Chris started their research on the roads that were taken by Bob and Ann before the civil war. Taking into account that the urban Lebanese fabric has witnessed a considerable change over the last fifty years, many of these roads had been replaced by highways and most of the old shops had been demolished or renovated. Once they had managed to find each respective road, a specific methodology of work was put in place by the photographers in order to achieve consistency in all 27 photos.

Bob and Ann went from the Phoenicia Hotel in Beirut to the ruins of Baalbek in the Bekaa Valley. All of their photos were taken in these locations and on the roads leading from one location to the other and back. Their numbered archive and Ann's notes were what allowed Chris and Noel to retrace the exact journey and start with the very first shot the couple had taken on their way to the Temple of the Sun in Baalbek. From the first photo to the very last, the artists would locate the area where the image was taken and Chris would take a photo first, handholding his camera and using the left stereoscopic image as a reference (stereo cameras take two photos of the same scene at the same time but with a slight shift that creates the three-dimensional feeling once viewed using the view-master). Without knowing the exact spot where his colleague stood, Noel would then take his own photograph of the same scene but using the right photo as a reference.

Once they had completed the same journey that Bob and Ann had, the photographers developed the films and scanned each and every scene using a technique known as "sandwiching". The way it works is that both negatives corresponding to the same scene are placed on top of each other and scanned together. This experimental process produces a two-dimensional photograph that evokes the simulacrum of three-dimensional space felt when looking through the view-master (figure 2).

By faithfully going back over the American tourists' journey, both the shooting technique and final product resemble a revival of history and of places (the state and condition of the revisited locations having, for the most part, extensively changed). The images having been produced by two distinct lenses and from two different perspectives (Coekin's and Nasr's) represent a duality or a split of vision. The subjective dimension is no longer 
the outcome of one photographer but of two, bestowing a double subjectivity on each respective image. The photographer's identity is now twofold, a dual identity. While this duality might be read in a number of ways, what is proposed here is that it resembles a rift, not only at a photographic level but most importantly, as a symbol of the fissure tearing apart Lebanese identity, where space and time in the images appear to fluctuate in the "rift [which is] between the appearance and essence of a thing (Morton, 2013)." Space and time appear and disappear, they do not adhere to any consistent definition, like the Lebanese identity which vacillates between one and the other.

\section{The Rift Space}

To support this argument, let us proceed with a simple description of the work of the two photographers. Amongst the many elements and features that can be described, the images present a duplication of the same objects and individuals. The duplicated objects and individuals are not on the same scale and their overlapping interrupts the continuity and more precisely the clarity of the objects presented. The overlapping of the images and duplication of entities causes a visual interception in the shapes of the different elements of each final "sandwiched" photograph, where the light, shade, shadows and the illusion of gravity do not meet, all of which causes an interruption of the fullness of the objects, as if they were somehow defective, very much like the Lebanese identity (figure 3).

In a distinct reading of the images, which inspects the space/time/movement aspect, the photos reveal dynamics and motion which cannot be studied through moving objects or flow of atmospheres (waves, clouds and so forth), but rather a motion that reflects a transition or change in the overall space/time definition and status. This will be discussed in more detail later.

In a theoretical dimension, the amplification, interception and escape into a new definition of space cause a loss of scale, whereby the absence of objects and sense of movement detected in Coekin and Nasr's photos become more of an experimentation on illusory spaces in flat images. An experimentation which questions real space/time presence and illusions, and which connotes the role of photography in history recording, particularly at times like those experienced during the Lebanese conflict and the perceptible feeling of Otherness in its culture. One might add that the attempt to generate an illusion of absence of space in these images could also be interpreted as the portrayal of the complexity of Lebanese identity, and the artists' distancing themselves from it and their choice of narration or lack of narration of its history.

\section{Intimating Scale and Borders of Space}

The illusory aspect of these images has not been established by the conventional spatial illusion that the foreground, mid-ground and background distribution of figures and objects, which habitually set the depth and sense of space in any flat image, give out (Gepshtein, 2001), the illusion is born from an aim to fake the depth of the space in such a way that it appears to be totally absent. Instead of representing the space per se, the photos become a representation of its absence (figure 4).

The absence can be detected in the amplification of the scale of the entities present in the photographs; an amplification which questions any realistic (yet illusory) perception of space and time. In reference to Paul Virilio's A Landscape of Events, this amplification of scale, which is also an amplification or falsification of time, is how media (television in the case of Virilios' discussion) is subjecting real time and space to new perceptions and illusions (Virilio, 2000). An instance of that is what Virilio refers to as "optical magnification," and develops by explaining how "the optical magnification of our natural environment is emerging at this fin de siècle as the final "frontier," the last horizon of technological activity." In this sense, television flattens images with lenses that magnify any point of our real natural environment, representing it with new exposures that are 
not real at distances and which are not constant (the camera zooms in and out, advances and reverses). Virilio further clarifies:

If you get rid of distances, in fact, and this has already happened with recent development of telecommunications, you must also get rid of borders. Not just the political borders of nation-state...you must also abolish the aesthetic "border' of the things that surround us, in favor of one ultimate boundary in time, that of the acceleration of the optical commutation of the appearance of a world wholly telepresent, twenty-four hours a day, seven days a week. (46)

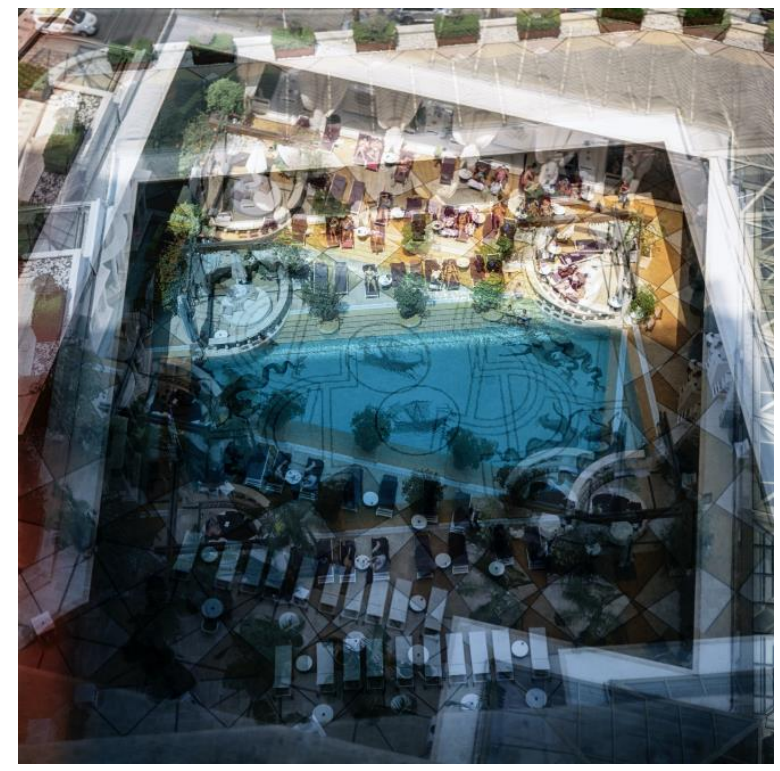

Figure 3: "Sandwich" technique revealing distinct characteristics

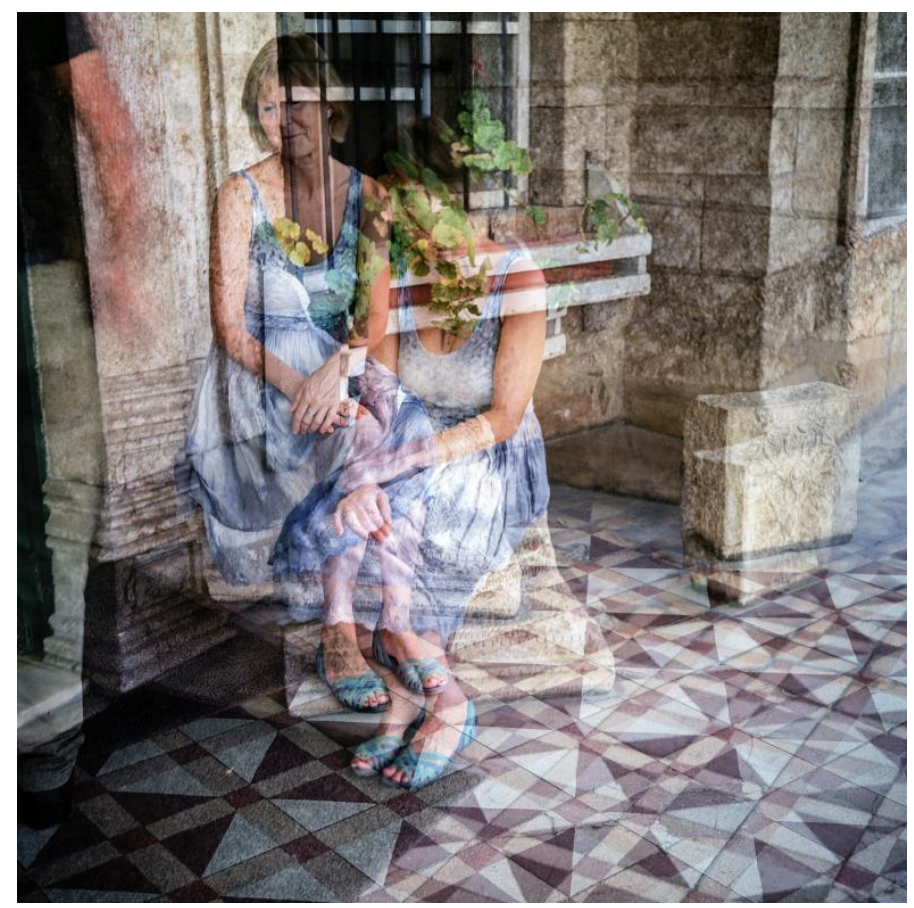

Figure 4: Amplification of objects

In such an argument, the technological activity and advancement which disperse distances by magnification, amplification or any other re-questioning of the real scale of things, intimate the border of things as well. The 
real-natural appearance of objects and natural environment is manipulated, at least aesthetically, causing any consistent relation with the surrounding nature to vanish. The camera's in and out gaze at the objects, and the image presentation on television sets the configuration of objects into realities of space and time other than natural realities. Real space and time become absent, giving way to other dimensionalities and scales.

"The Distance is Always Other" offers a similar dispatch from real time and space. The amplification and inconsistency of scale of the duplicated entities is an inconsistency of dimensionality and referencing (basic components of space), hence an affiliation to no space. What is more, the project further announces the lack of real space twice: the first time being with the amplification of scale or the simulacra effect, and the fact that real scale can be visualized through fake scaling. The second time, more insistently with a co-presentation of two fake scales. Not only is scale inconsistent, but it is a double inconsistency, which brings about the perishing of the very ethos of figure presentation. As if the image insisted on manifesting its departure from real time and space, it does so twice so as not to negotiate any possible recognition of normal settings. No way back and no sliding back into any real conditions. A final and definite absence of the oneness of space.

\section{Remote Presence of De-voided Objects}

The absence of space can also be discussed in the intercepted fullness of objects. An effect which tends to flatten figures and de-void them of any visual gravity. The fact that we cannot record a complete reading of the fullness of objects and their weight/gravity, something usually achieved through the play of light, shade and shadows, and which is now being interrupted by the juxtaposing of entities and consequently a crossing of light, shade and shadows, subjects the entities to flattening and loss of gravity. Objects become ghosts, abstract and light; de-voided objects (figure 5).

The ghostly attribute reminds us of the concept of hauntology, which was initiated by the deconstructivist discourse, mainly Derrida. In "Dialogue Between Fukuyama's Account of the End of History and Derrida's Hauntology," Chris Hughes reflected on this notion by writing:

Hauntology is the idea that there is something from the past which is always present in the present; and, also, that this something is waiting for its return in a future to come. Derrida invokes the metaphor of a specter (or specters) to embody those things which are always there and always waiting to come (or come back). The specter is thus both past and future; it is from the past, but waiting to come back. The metaphor of a specter haunting the present establishes the idea/image of the existence of something ghostly which stands over and outside the present, something which does not belong to time, and is waiting to come. (Hughes, 2013)

The analogy of the ghostly appearance in Derrida's hauntology is a function with two notions: history and origin. In the first one, the objects that might appear as ghosts have an oscillating relationship with the pastpresent-future, where figures belong to the past yet also to the future while simultaneously being the future of the past. Accordingly, objects vacillate between their past, present and future. Still taking into account the oscillation in the linearity of history, the other notion sees objects and figures lose their originality. They appear or reappear in such a way that it becomes hard to define their precise and temporal origin. Ghostly figures hence adhere to no history or origin.

To project this proposition into the work of Coekin and Nasr, the hauntology inspected in the objects/figures (due to the intercepted fullness) manifests this de-originating of the present entities from their history - echoing as will be suggested below, echoing the Lebanese's search to deny history (at least the history of the other Lebanese).

Yet what becomes interesting with this ghostly attribute of the work is how it might echo and reflect through the viewers of the project's exhibition. One wonders how it might feel and what it might mean to different viewers to look at figures and ghosts de- voided or their origin yet staring back at them? Does this inform the viewer 
about a similar personal possibility wherein he/she might become de-voided of his/her origin? Or does it remind them that what they are looking at is only an image, and consequently they exist in real time, space and history where they have to deal with their crises, conflicts and their other Lebanese accordingly?

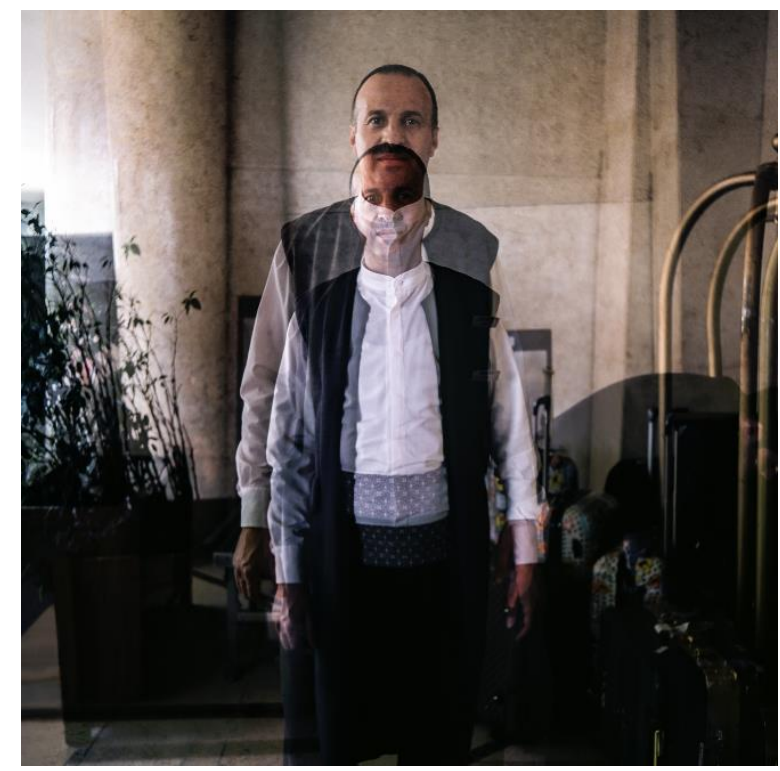

Figure 5:Ghostly image

Both Carl Kandutsch and John Freeman offer scenarios of the significance of (ghostly) images to such viewers. In "A Gaza Photograph," Kandutsch wrote about their various relations and levels, where in one instance he refers to a photograph of a boy from Gaza sitting between ruins (Credit Ahmed Hjazi) and staring "at the camera and therefore at the viewer (Kandutsch, 2016)." However, Kandutsch continues by telling us that the boy "cannot see us because we are invisible. The photograph's effect is unsettling...we are not there, and we cannot go there; we cannot make our present his present, not now (Kandutsch, 2016)." What is established is therefore a sort of mutual affection of both presents: the boy's or ghost's present that stares at the camera and recognizes the presence on the other side regardless of the invisibility of that world; and the other invisible world which is the real us sympathizing with the boy (or ghost) but not being able to cross to the space of the image. Hence, in essence, what is established is no more than infertile recognition. Perhaps a desired infertile recognition.

Freeman, on the other hand, in his reading of Tupac's holographic resurrection during Coachella's concert in 2012, believed that the audience's reaction to the ghost of Tupac was once again a question of the visibility and invisibility of Tupac and the audience (Freeman, 2016), but he further subjected the event to the discussion of amnesia, memory, sorrow and confrontation, or what he named "shocklike confrontation (Freeman, 2016)." The holographic present and not-present of Tupac was a direct confrontation of a past-alive-now-dead singer with his now-and-here alive audience, which was rather a shocking dialogue between the living and the dead. Yet "the genuine hauntological spectacle is never so forgettable and anesthetic." In the performance, "the audience is encouraged to forget the past and its attended (Freeman, 2016)." Consequently, the haunted Tupac is at one moment a sorrow reminder of his own death, while at another a not-so-sorrow ghost presence at Coachella's now-concert.

The ghostly figures of Coekin and Nasr might have aimed at both paradoxical empathies. Being a glance and a contemplation all at once, one could say that they resemble the never-so-forgettable past of the country (taking into account the fact the photographers had retraced a set of images shot prior to the Lebanese civil war, hence indirectly turning their work into the revival of not so easily forgettable historical moments). This is further confronted with-the representation of the places that were shot decades ago with the now places overlaid with this ghostly effect. The confrontation therefore effectively takes place between the real past time, the now ghosts 
of the photographic figures and the invisible real audience and viewers; an interplay of existence and no existence. A concurrence of remembrance and denial. As the audience is captivated in this interplay, the overall feeling tends to be one of sorrow and leisure at the same time; sorrow for the past and for what has been lost, and leisure for being invisible, as if in total disguise from any sort of history. They probably think "we are not there, and we cannot go there (Kandutsch, 2016)," we do not want to be there. Let the other be there instead.

\section{Stagnant movement and the loss of memory and history}

Interestingly, in yet another interpretation, the images appear to express a space-time-movement reading, which deviates from the previously established interactions between these components. Movement, according to Descartes, is measured through the time an object needs to cross from one point to another through 3D axial space (XYZ). Yet the complexity which is suggested in post-modern discourses related to how movement is not formulated or not a function of the linearity of time and axiality of space has initiated other possibilities of conceiving and perceiving it. In this light, instead of being sensed by objects in space or flow of entities in time, movement could be inspected through still objects or stagnant spaces. Much like the photos of Coekin and Nasr tend to reveal movement within the objects and figures themselves, as opposed to these objects and figures appearing to belong to the space that surrounds them. Deleuze and Guattari suggested such movement resembled nomadism when they wrote:

They are nomads by dint of not moving, not migrating, or holding a smooth space that they refuse to leave, that they leave only to conquer and die. Voyage in place: that is the name of intensities, even if they also develop in extension. (Deleuze and Guattari, 1987)

The sense of movement here is created by intensities that propagate through a place or an object and not objects that voyage in time and space. In such a situation, these intensities become a deviation in the existence of the objects. An intensity or movement which reallocates the object to a different reality. The duplication responsible for this feeling of movement is an identical repetition of an entity - the rock, the pool, the individual-so the entity moves to represent itself again and to suggest its presence as another being, hence the creation of intensity between the two beings. While the movement belongs to a specific place, it fluctuates between one existence and another alternative yet same existence. It is very much an ontological shift from one existence to another of the entities presented. A shift that requires no space but rather the total absence of it, where entities can be freed from the physical constraints of any space in order to be intensified in another. But to what end, one might ask?

The amplification of scale, the hauntological realm and these stagnant intensities which reverberate like a denouncement of space are indirectly denouncing history and dispersing its records. If the recording of history and memory through photography has to establish its narration through spaces - stories, history and events happen in places and spaces and geographies (De Certeau 1984) - it would denote that the absence of spaces, as in the photos of Coekin and Nasr, would denote a likewise absence of history, a sort of intentional act to disperse the history of the places in which the shooting took place, disregarding the geography of the place through this act, and doing away with any movement that may have existed en route to the different shooting locations, consequently also discarding the very existence of those Lebanese sites.

The Lebanese do not like to adhere to a single place and single history, just as they would rather not belong to a single historical narration due to their constant disagreement about their geographical identity, brought about by the on-going identity crisis in the country since its independence. By removing space from its images, "The Distance is Always Other" records and represents this Lebanese phenomenon. Instead of addressing the memory, history and places of the Lebanese, through the metaphor of the ghost spaces, it touches upon the fact that for each Lebanese person, there is an "Other" memory and preferably no memory at all. In reference to Hani Darwish's remark on the Lebanese's scattered and fragmented affiliation, Fadi Tofeili wrote in "He Was a Specter that Moved in a Dreamlike Haze Between the Pictures": 


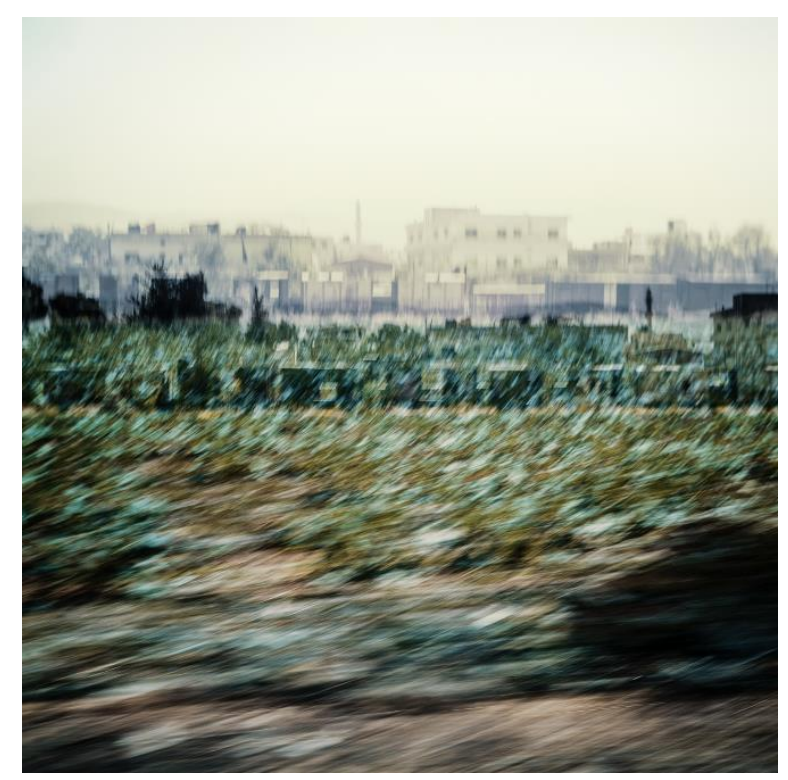

Figure 6: Stagnant movement

Once during his short life, on his second visit to Lebanon, Hani said to me that the actual distance here on the ground between two specific locations is not accurately represented on maps of this small country; that on the terrain itself, the distance is always other. For here it extends through the onerous and entangled details of the country. When drawn as a line on the map, the distance is diminished, limited, and the meager kilometers deduced on the basis [of] the bar scale at the bottom of the page do not do its reality justice. Distances here, he would say, are not mere kilometers or miles traversed on the roads, they are not abstract distances connecting places. (Tofeili, 2018)

What Darwish and Tofeili are suggesting here is that the Lebanese never appear to be able to fall within one real bar scale, they exist in spaces that cannot be measured by map distances, because the differences and disagreements that exist between them cannot be logically projected into the distance that separates them. There is too much otherness at short distances. Space extends between them not as a real measurement, but rather, as Deleuze and Gauttari see it, as an extension only for them to travel each away from the other yet not necessarily by moving from place to place. The movement in Coekin and Nasr's images is therefore representative of the intensities of otherness that the Lebanese generate from the confusion and chaos surrounding their national identities, generated only to distance themselves from each other in stagnant places. The photographers even suggest that the Lebanese camouflage themselves in order to extend further into otherness, and that their camouflage is twofold. The first through the duplicated deviant scale which disperses and denies any referencing, thus betraying their Lebanese reality. The second and harsher instance being when they camouflage themselves with the absent space, appearing like ghosts that cannot be haunted and not only betraying themselves through this process but also denying the other's right to exist.

\section{Conclusion}

"The Distance is Always Other" is essentially an attempt to analyze the notion of the Other by touching upon the fragile issue of the Lebanese national identity crisis and in particular the feeling of chaotic co-existence of distinct cultural identities within a single land. Coekin and Nasr managed to manifest this through the multifold aspects and dimensions which likewise coexist within their ambitious project. The photographers' use of alternative technical expressions through their twin images and the unconventional spatial and temporal dialogue expressed through their work function as a form of replica of the Lebanese identity's tumultuous state. Their dissection and blurring of space and their presentation of time in inconsistent leaps makes the final images 
of the project echo the diversity and distance between the Lebanese, a distance which is not measured by actual dimensions but by the desire of detachment the Lebanese feel towards each other.

Such disturbance in national cohesion and sense of belonging is possibly a phenomenon which is on the increase throughout the world, particularly given the scale of inter-nationalism and human flow. Such events invite an urgent rethinking of the manner in which we communicate and express our visual understanding and reflections in a rapidly changing world.

\section{References}

Barrett, L., 2000, Compositions of reality: Photography, history, and Ragtime. Modern Fiction Studies, 46(4), 801-824.

Campbell, D., 2012, Cultural governance and pictorial resistance: reflections on the imaging of war. Journal of Philosophy: A Cross-Disciplinary Inquiry, 7(18), 57-73.

De Certeau, M., 1984, The Practice of Everyday Life (London, U.K.: University of California Press).

Deleuze, G, Guattari, F., 1987, A Thousand Plateaus: Capitalism and Schizophrenia (London, U.K.: Continuum).

Derrida, J., 1976, Of Grammatology (Baltimore, USA: The Johns Hopkins University Press).

Freeman, J., 2016, Tupac's "Holographic Resurrection": Corporate Takeover or Rage against the Machinic? Ctheory 21 cL:21C014 (www.ctheory.net) (date of access: 14-8-2018).

Gepshtein, S., 2001, The Perceptual Organization of Visual Space-time. Dissertation, University of Virginia.

Gurevich, B. and Yashina, V. V., 2012, Descriptive Approach to Image Analysis: Image Formalization Space. Pattern Recognition and Image Analysis, 22 (4), 495-518.

Hughes, C., 2013, Dialogue between Fukuyama's Account of the End of History and Derrida's Hauntology. Religions, 4: 336-350.

Kandutsch, C., 2016, A Gaza photograph. Ctheory 21c:21C024 (www.ctheory.net) (date of access: 14-8-2018).

Kandutsch, C. 2015, A Yarmouk Photograph, Ctheory 21c: 21C005 (www.ctheory.net) (date of access: 14-82018).

Khalaf, S., 2002, Civil and uncivil violence in Lebanon: The History of Internationalization of Communal Conflict (New Yor, USA: Columbia University Press).

Krauss, R., 1986, The Originality of the Avant-Garde and Other Modernist Myths (Cambridge, USA: MIT Press).

Loevlie, E., 2013, Faith in the Ghosts of Literature. Poetic Hauntology in Derrida, Blanchot and Morrison's Beloved. Religions 4: 336-350.

Minghelli, G. 2016, Icons of remorse: photography, anthropology and the erasure of history in 1950s Italy. Modern Italy, 21 (4): 383-407.

Morton, T., 2013, Hyperobjects: Philosophy and Ecology After the End of the World (Minneapolis, USA: University of Minnesota Press).

Nickel, D. 2001, History of photography: The state of research. The Art Bulleti 83(3): 548-558.

Tofeili, Fadi 2018, He Was a Specter that Moved in a Dreamlike Haze Between the Pictures. In: The Distance is Always Other (London, U.K.: Dongola Limited Edition).

Virilio, P., 2000, A Landscape of Events (Cambridge, USA: MIT press). 